\title{
Buen Vivir y colonialismo: hacia pedagogías decoloniales en América del Sur
}

'Buen Vivir' and colonialism: towards decolonial pedagogies in South America

\author{
Rolando Angel Alvarado \\ rolando.angel.alvarado@gmail.com \\ Instituto de Música \\ Universidad Alberto Hurtado \\ Santiago, Chile \\ ORCID: https://orcid.org/0000-0002-1800-2667
}

doi: 10.7203/LEEME.48.21662

Recibido: 25-09-2021 Aceptado: 04-11-2021. Contacto y correspondencia: Rolando Angel Alvarado, Instituto de Música, Universidad Alberto Hurtado, C/ Almirante Barroso, 31, C.P. 8340540 Santiago de Chile, Chile.

\begin{abstract}
Resumen
El Buen Vivir es una noción polisémica y contrahegemónica basada en cosmovisiones de pueblos nativos de América del Sur, entendiéndose como Sumak Kawsay en quechua, Suma Qamaña en aymara y Küme Mogñen por el pueblo mapuche. El presente estudio busca comprender la educación musical en América del Sur desde el Buen Vivir con el afán de hallar pedagogías decoloniales en un territorio colonizado, utilizándose el método comparativo constante mediante procesos de categorización y codificación con el afán de plantear la plausibilidad de una teoría emergente. Los resultados revelan tres modelos colonialistas: 1) el modelo tridentino aplicado en los tiempos de conquista representa el polo opuesto al Buen Vivir; 2) el modelo conservatorio provoca la crisis espiritual que tensiona la fe y la razón y; 3 ) el pragmatismo es visto como un gatopardismo colonial. Desde el decolonialismo, se observa que el musicar resuena con el enfoque sociomusical, favoreciendo la participación y la construcción de la identidad sociomusical. Se concluye que pedagogías basadas en el Buen Vivir sanarían las relaciones comunitarias, interculturales, medioambientales y espirituales, tanto de la gente nativa como mestiza de América del Sur, ya que tales relaciones sociomusicales actuarían como nutrientes de la identidad personal y colectiva.
\end{abstract}

Palabras clave: Capital sociomusical; decrecimiento; capitaloceno; sincretismo.

\begin{abstract}
'Buen Vivir' is a polysemic and counter-hegemonic notion based on world views of native communities from South America, which is understood as Sumak Kawsay in Quechua, Suma Qamaña in Aymara, and Küme Mogñen by Mapuches. The current study aims to understand music education in South American from 'Buen Vivir' to find decolonial pedagogies in a colonized territory, using the constant comparative method through procedures of categorization and coding in order to propose the plausibility of an emergent theory. Findings reveal three colonial models: 1) the Tridentine model implemented in conquest times represents the opposite side to 'Buen Vivir,' 2) the conservatory model provokes a spiritual crisis when faith is confronted with reason, and 3) the praxialism, which is seen as a colonial gatopardism (superficial change). From decolonialism, the musicking resonates with the sociomusical approach, favouring participation and construction of the sociomusical identity. We conclude that pedagogies based on 'Buen Vivir' may cure communal, intercultural, environmental, and spiritual relationships, both in natives and mestizo people from South America, as those sociomusical relationships serve as nutrients for personal and collective identity.
\end{abstract}

Key words: Sociomusical Capital; Degrowth; Capitalocene; Syncretism. 


\section{Introducción}

Tomando como base el nivel de ingreso medio de habitantes y la jerarquía de riqueza nacional, Fernández et al. (2014) establecen que el Norte Global se compone por países desarrollados que cuentan con estabilidad política-económica, altos índices de esperanza de vida y tecnologías avanzadas; mientras que el Sur Global comprende al resto de países en vías de desarrollo que han sido colonizados, que sufren crisis sociales y que basan su modelo económico en el extractivismo. Es decir, hablar de Sur Global es referirse a la periferia del mundo, poniéndose el foco en las prácticas colonialistas y los movimientos insurgentes que buscan instalar el decolonialismo desde una perspectiva local que preserve los recursos naturales y culturales, que fomente las acciones comunitarias de igualdad de oportunidades y que conmemore con perspectiva histórica a quienes han sufrido vulneraciones biopsicosociales por causas colonialistas. En la educación musical sudamericana, las prácticas colonialistas se expresan mediante los modelos jesuita y conservatorio que se introdujeron desde Europa a través de la conquista luso-española y la replicación del Conservatorio de París, respectivamente (Shifres y Gonnet, 2015), mientras que las prácticas decoloniales se conciben desde el enfoque sociomusical (Angel-Alvarado, 2018; de Branco y Santos, 2021; Guerrero, 2007), ya que la participación activa y comunitaria es determinante para la construcción de la identidad personal y colectiva.

En este escenario, cobra valor el Buen Vivir como noción decolonial en América del Sur, pues implica interrelacionar de manera iterativa lo medioambiental con lo económico y lo ciudadano desde una perspectiva centrada en el sentido de comunidad. En concreto, los pueblos originarios de América del Sur practican el Buen Vivir desde el período prehispánico con el afán de entrelazar lo natural, lo espiritual, lo comunitario y lo holístico (Friggeri, 2021), denominándose Sumak Kawsay en la cultura quechua, Suma Qamaña en la lengua aymara y Küme Mogñen en la cosmovisión mapuche. Es imperioso discutir el Buen Vivir en la educación musical desde la reflexividad porque las prácticas pedagógicas deben legitimar las diferencias culturales para identificar prácticas colonialistas en contextos que aboguen por el decolonialismo (Shifres y Rosabal-Coto, 2017). Cabe señalar que el decolonialismo se entiende como un enfoque que valora, dignifica y perpetúa el conocimiento local en sus propios códigos de expresión, sin rechazar ni privar el acceso al saber colonial. Por consiguiente, la reflexividad ahonda en la estructura sistémica desde una perspectiva intercultural, abarcando "el pasado, el presente y el futuro que se anticipa" (Westerlund et al., 2020, p.4).

El presente estudio propone como objetivo comprender la educación musical en América del Sur desde el Buen Vivir porque, más allá de las divisiones fronterizas que dan lugar a identidades nacionales, se observa el surgimiento de pedagogías decoloniales que se contraponen a las pedagogías colonialistas que invisibilizan o academizan los saberes locales y ancestrales. Por consiguiente, es imperioso observar si estas pedagogías emergentes se piensan desde el Buen 
Vivir o, por el contrario, son prácticas colonialistas que se camuflan como acciones decoloniales, tomando como base teórica el decrecimiento.

\subsection{Del decrecimiento al Buen Vivir: La praxis ancestral por sobre la teoría modernista}

El decrecimiento es un concepto que busca equilibrar las economías mundiales desde una perspectiva "posfósil y globalmente justa del hiperconsumo" (Schmelzer, 2021, p.154), volviéndose así necesario que el Norte Global baje sus índices de consumo y que el Sur Global los aumente para reducir los niveles de pobreza. Así, los países del Norte se ven instados a comprometerse con un modelo de justicia ambiental que sirva para reducir la huella de carbono de manera sostenible, no solo por la deuda histórica que tienen tras explotar y usurpar los recursos naturales e intelectuales del Sur Global (Rivera, 2018), sino también porque su desarrollo tecnológico ha tenido consecuencias socioambientales que aquejan principalmente a los países del Sur Global. Por lo expuesto, el decrecimiento se plantea como una forma de activismo que desafía la hegemonía de producción y consumo desde una perspectiva redistributiva con el propósito de promover principios de sustentabilidad, bienestar y justicia social.

Sin embargo, el decrecimiento no resolvería las adversidades que plantea el Antropoceno y el Capitaloceno -entendidos como las repercusiones que tiene el modelo industrial en el clima, la sociedad y las especies no humanas mediante relaciones capitalistas basadas en estructuras de poder político-económicas- porque, según Nieto (2021), la construcción teórica del decrecimiento queda en buenas intenciones y en campañas mediáticas al observarse dificultades para reunir adeptos en los países desarrollados. En este sentido, Wright (2014) establece que la fragilidad del decrecimiento se comprende desde tres criterios utópicos interrelacionados entre sí. Primero, la deseabilidad cuestiona si el decrecimiento resuelve o no problemáticas intergeneracionales ligadas al cambio climático y la pobreza. Segundo, la viabilidad pone en duda si el decrecimiento se puede implementar o no de forma estable para que la sociedad pueda acceder a una mejor calidad de vida. Por último, la accesibilidad cuestiona si las condiciones y estructuras sociales permiten o no la implementación del decrecimiento. Por lo dicho, es plausible que la estrategia deseada no sea viable, así como también que la estrategia viable no sea necesariamente asequible por presiones sociales (Schmelzer, 2021).

Por ejemplo, los países del Sur tienen deudas que pagar a los países del Norte, pero dicho endeudamiento se traduce en hipotecas ecológicas que los países desarrollados jamás podrán saldar (Lessenich, 2019). Por lo tanto, el sentido de equilibrio entre las economías mundiales es deseable, pero no es viable porque la hegemonía económica del Norte ha convertido en zona de sacrificio a numerosos territorios del Sur Global (Merlinsky, 2021). La accesibilidad también refleja escenarios complejos y de cambio en América del Sur, pues las ciudadanías se han revelado contra las estructuras de poder. Reflejo de esto son los procesos migratorios en 
Venezuela, las agitaciones sociales en Chile, Colombia y Ecuador, así como también las crisis político-económicas en Argentina, Bolivia, Brasil, Paraguay y Perú.

En contrahegemonía al decrecimiento, existe el Buen Vivir en América del Sur, el que se refiere a una noción polisémica que ha confrontado el sistema occidental de desarrollo (Unceta, 2013) desde una visión cultural-ancestral que piensa de manera armónica e interrelacionada el medioambiente, la economía y la ciudadanía comunitaria. Ciertamente, los pueblos originarios de la región tienen diferencias culturales entre sí, pero si hay algo que tienen en común es el sentido de comunidad que da cuenta del Buen Vivir (Friggeri, 2021). A diferencia del decrecimiento, el Buen Vivir es un saber local y ancestral de los pueblos originarios. Sin embargo, sus denominaciones varían según las lenguas nativas porque el indigenismo acusa de que el Buen Vivir carece de la dimensión espiritual al mezclarse con elementos modernistas (cf. Viteri, 2002).

Así, en el quechua se denomina Sumak Kawsay y se funda en las tradiciones ancestrales de la cosmovisión andina, de modo que se establecen vínculos con la Pachamama, la naturaleza, los mitos y los ritos, poniéndose el foco más en lo pleno que en lo bueno (Oviedo, 2011). En aymara, se llama Suma Qamaña, dando cuenta de una vida cosmocéntrica y holística que no hace distinciones entre lo vivo y lo inerte, sino que el todo es parte de un cosmos que se comprende como organismo vivo en el que con-vivimos en un sentido eco-filosófico (Estermann, 2012). Por lo tanto, el progreso y desarrollo no se entiende cuantitativamente, sino que cobra relevancia la distribución justa y la prudencia en el uso de los recursos. Un último ejemplo, el Küme Mogñen de la cosmovisión mapuche representa el bienestar dentro de una relación horizontal con la tierra, la naturaleza, la comunidad y la familia, desvelando un equilibrio holístico y cosmológico en la forma en que la persona se relaciona con otras, con su entorno natural y con lo sobrenatural (Bermedo, 2015). Por todo lo expuesto, es plausible aseverar que las ideas de crecimiento y desarrollo son irrelevantes en los pueblos originarios de América del Sur, ya que:

el futuro está atrás, es aquello que no miramos, ni conocemos; mientras al pasado lo tenemos al frente, lo vemos, lo conocemos, nos constituye y con él caminamos. En este camino nos acompañan los ancestros que se hacen uno con nosotros, con la comunidad y con la naturaleza. Compartimos entonces el «estar» juntos con todos estos seres; seres que tienen vida y son parte nuestra. El mundo de arriba, el mundo de abajo, el mundo de afuera y el mundo del aquí, se conectan y hacen parte de esta totalidad, dentro de una perspectiva espiral del tiempo, no lineal (Larrea, 2010, p.20).

A estas visiones indigenistas se agrega una corriente estatista del Buen Vivir ligada al pensamiento neomarxista, pues se ha institucionalizado en las constituciones de Ecuador y Bolivia. El Buen Vivir estatista no ha estado exento de polémicas porque, mientras los gobiernos lo entienden como una alternativa al neoliberalismo, los pueblos originarios lo conciben desde la plurinacionalidad y la interculturalidad (Rivera, 2018). Así, Bretón Solo de Zaldívar (2013) plantea que el Buen Vivir estatista es una mezcolanza de planteamientos étnicos, platónicos, aristotélicos, cristianos y humanistas que banalizan la visión indigenista porque el sentido de comunidad se reduce a políticas asistencialistas. Es decir, los gobiernos toman los principios del 
decrecimiento para ajustarlos al Buen Vivir, camuflando los discursos de pobreza como discursos hacia las comunidades indígenas, manteniéndose las brechas y estereotipos hacia los pueblos originarios (Friggeri, 2021).

Todo lo anterior revela diferencias entre decrecimiento y Buen Vivir indigenista, ya que el primero se piensa desde el sistema-mundo, mientras que el segundo se aborda desde una visión local. De ahí que Schluchter (2011) conciba la comunidad como lo ancestral, la vida auténtica y duradera, así como también lo vivo, lo afectuoso y lo orgánico; y la sociedad como lo nuevo, lo pasajero, lo mecánico, lo competitivo y lo artificial. La dicotomía entre lo global y lo local deja entrever que el decrecimiento y el Buen Vivir estatista se vuelven inviables porque se piensan a nivel macrosocial, planteándose como novedades políticas que buscan marcar diferencias con otras ideologías, sin alterar el sistema de dominación que provoca segregaciones y exclusiones (Larrea, 2010). Al contrario, el Buen Vivir indigenista "no es solo una propuesta teórica, sino que constituye también una práctica social que, aunque restringida, debería servir como inspiración para transformar la realidad actual" (Unceta, 2013, p.201).

Vale agregar que existe una tercera corriente del Buen Vivir denominada postdesarrollista, pues rechaza las ideas de desarrollo y crecimiento porque se conciben como mecanismos de dominación, poniendo así la sustentabilidad como pilar para la convivencia. Sin embargo, la corriente postdesarrollista altera la visión indigenista porque permite que personas que no pertenecen a pueblos originarios puedan construir su propia forma de Buen Vivir sin tener que renunciar a su modo de vida, surgiendo así movimientos activistas (Cubillo-Guevara, 2016). Tal corriente fue adoptada en Europa por perseguir los ideales del decrecimiento, medida que fue criticada por el indigenismo y el estatismo debido a que tergiversa la cosmovisión nativa y carece de un pragmatismo político (Oviedo, 2011). La corriente postdesarrollista, como variante del decrecimiento (Cubillo-Guevara, 2016), aun cuando se presenta como deseable, su viabilidad y accesibilidad son discutibles porque la comunidad puede desarticularse al cumplirse el cometido activista o al cambiar los intereses personales de quienes la integran. La comunidad es frágil; si las personas cambiaron una vez su modo de vivir, es plausible que se retracten o busquen otra forma de vida después.

\section{Método}

Se utiliza el Método Comparativo Constante (MCC) porque los procedimientos de recolección y análisis dan cuenta de un proceso espiral que busca delimitar una teoría emergente tras saturarse teóricamente dos categorías conceptuales (Carrero et al. 2012). En concreto, los datos se recopilan mediante la revisión de literatura educativo-musical contextualizada en América del Sur, analizándose las categorías de manera comparativa e integrativa según procedimientos de codificación abierta, axial y selectiva (San Martín, 2014). Así, el MCC se implementa de manera deductiva porque las categorías se conceptualizan y amplían con el afán 
de levantar una teoría sobre la educación musical en América del Sur desde la visión del Buen Vivir. Esto no implica llevar a cabo procesos de verificación ni probatorios, sino que el estudio se limita a plantear la plausibilidad de la teoría emergente (Osses et al., 2006). Por lo expuesto, se establecen a priori dos categorías conceptuales:

Prácticas educativo-musicales implementadas en América del Sur.

Expresión del Buen Vivir en la educación musical de América del Sur.

En términos procedimentales, primero se conceptualiza cada categoría conceptual mediante códigos abiertos conforme la interpretación investigadora, prevaleciendo la recopilación de hechos documentados en lugar de reflexiones o presunciones para asegurar principios de objetividad durante la codificación abierta (San Martín, 2014). Una vez alcanzada la saturación teórica, se procede a la codificación axial, entrelazándose los códigos abiertos de ambas categorías conceptuales con el afán de determinar interacciones, condiciones y consecuencias respecto a las pedagogías, sean coloniales o decoloniales, y su comprensión desde el Buen Vivir. La tercera y última fase procedimental, la codificación selectiva, implica depurar la categorización mediante la selección de los códigos abiertos y axiales que permiten construir y explicar una categoría central, la que se entiende como la teoría emergente (Carrero et al., 2012). En el presente estudio, la codificación selectiva debería orientarse hacia la definición de principios pedagógicos decoloniales, tomando el Buen Vivir como base epistemológica.

\section{Resultados}

\subsection{Educación musical en tiempos de conquista}

En el siglo XVI, llegaron a América del Sur músicos y misioneros europeos, quienes utilizaron la música como medio de evangelización ante las comunidades nativas. La música y su educación fue regulada e implementada por la Iglesia, replicándose en la región las mismas instituciones y prácticas que ya estaban instaladas en Europa (cf. Pedrotti, 2009). En este marco, Barriga (2006) hace hincapié en cuatro cuestiones: 1) los repertorios utilizados eran casi los mismos empleados en Europa; 2) los maestros de capilla eran principalmente compositores europeos, pasando a segundo plano los músicos criollos; 3) si bien el canto llano era la puerta de entrada a la práctica musical, la polifonía se incluía en las prácticas eclesiásticas y; 4) la educación musical se institucionalizó en los colegios seminarios, estableciéndose criterios de acceso elitistas en el Virreinato del Nuevo Reino de Granada porque solo podían acceder quienes provinieran de matrimonios españoles legítimos. Esta educación musical formal permitió implementar métodos y tratados didácticos provenientes de Europa orientados a la lectura musical, el solfeo y la práctica instrumental, surgiendo con los años propuestas metodológicas locales (cf. Allende, 2014). 
Tal institucionalización responde a los acuerdos establecidos en el Concilio de Trento, pues, dado que se le comenzó a exigir un comportamiento moral al clero, la Iglesia Católica Apostólica y Romana debió instauran colegios seminarios para instruir y formar a novicios, misioneros y sacerdotes con la intención de marcar diferencias entre la ortodoxia y la herejía (Tánacs, 2002). Vale decir que el Concilio de Trento fue una política supranacional religiosa que buscaba frenar los movimientos protestantes dentro de Europa. Sin embargo, tuvo un impacto directo en la educación musical de América del Sur porque, además de su institucionalización en los colegios seminarios, primó la enseñanza del latín puesto que se introdujo el rito romano conforme a lo establecido en la bula papal Quo primum tempore. Esto no significa que las lenguas vernáculas se excluyeran, ya que la labor catequista daba lugar al sincretismo cultural (Baker, 2008), favoreciendo la hibridación entre lo europeo, lo africano y lo indígena (Bernand, 2014).

Por consiguiente, se observa una pedagogía musical institucionalizada por la Iglesia que sirve como medio evangelizador conforme a los ritos romanos, lo que comprende el canto llano, la notación musical, la incorporación de repertorio europeo y el uso del latín. En este marco, Shifres y Gonnet (2015) han denominado tal pedagogía como modelo jesuita, pues el arte colonizador eurocentrista se impone hegemónicamente, invisibilizando las expresiones de los grupos colonizados (Serrati, 2017). En otras palabras, el modelo jesuita implica procesos de aculturación porque el poder colonial erradica los elementos culturales del territorio conquistado para instalar los propios, incluso por la fuerza. Por ejemplo, los rituales andinos que implicaban entrar en estado de trance solían tildarse de satánicos por la Iglesia, al punto de que el doctrinero Bartolomé Álvarez solicitó, sin éxito, la intervención de la Santa Inquisición para erradicar dichas prácticas altiplánicas (Battcock, 2015). De ahí que Salinas (2000) enfatice que el Concilio de Trento utilizó la música como un recurso de adoctrinamiento político y religioso, dado que se censuraron las festividades locales por considerarse herejías, perversiones y paganismo, siendo sustituidas por celebraciones católicas. Estas fiestas y ceremonias religiosas, sin embargo, dieron pie al mestizaje cultural porque predominaba la música profana en lengua vernácula, la que se expresaba, por ejemplo, como romanesca, milonga o cueca (Bernand, 2014).

Las guerras de independencia no despojaron a América del Sur del modelo jesuita, puesto que, al menos en Chile, la educación musical se instaló en el sistema escolar en 1847 bajo el nombre de Canto Llano, en un marco curricular donde se priorizaba el aprendizaje del latín (Sepúlveda, 2017). Por último, agregar que la denominación de modelo jesuita es discutible, ya que, de la cifra total de misioneros que arribaron a América entre 1543 y 1820, el 56\% eran Franciscanos y solo el 13\% correspondía a la Orden Jesuita (Barriga, 2006). Por lo tanto, a nuestro entender, lo más apropiado sería sustituir la denominación de modelo jesuita por modelo tridentino, haciendo referencia a Trento. 


\subsection{Educación musical en la globalización colonial}

El Conservatorio de París da sus primeros pasos en 1795, presentándose como una nueva institución educativa que se propuso formar profesionales de la música en los ámbitos de interpretación instrumental, canto, teoría musical, composición, historia musical y danza. En este marco, Rhalizani (2020) expresa que el Conservatorio de París se volvió una institución pionera dentro de Europa en un momento preciso, pues los países pasaban por períodos de recesión debido a las constantes guerras. Las familias aristócratas y las monarquías estaban reduciendo sus gastos en arte, de modo que los artistas estaban buscando sustento por su propia cuenta, ya que no había mecenas dispuestos a financiarles. La figura institucional del conservatorio se volvió relevante no solo por la oferta educativa que provee cualificación formal a un saber musical, sino también porque contribuye a la empleabilidad de los artistas mediante acuerdos salariales.

Se han abierto conservatorios alrededor del mundo a lo largo de los años y América del Sur no ha sido la excepción. Esto desvela un colonialismo globalizado desde los inicios del siglo XIX porque la armonía tonal se instaló en los conservatorios mediante el análisis Schenkeriano (Moreira, 2020), el que está actualmente bajo cuestionamientos porque se le acusa de invisibilizar a compositores que están fuera del canon euro-génico. A esto, es imperioso agregar los afanes institucionales por academizar la música de tradición oral, puesto que los conservatorios suelen transcribir el repertorio popular en partituras (Holguín y Shifres, 2014) y, más aún, surgen escuelas de música popular en la región, institucionalizándose la tradición oral bajo estructuras eurocéntricas. La introducción del sistema tonal y academicista ha provocado el surgimiento de mitos colonialistas con respecto a la música andina (Salinas, 2000; Vera, 2014), pues, según Mendívil (2012), los pueblos originarios han sido representados por la academia como culturas estáticas en base a patrones idílicos del imperio incaico, pasándose por alto las cualidades sonoras de los artefactos que existían en el período prehispánico.

Así, el interés formativo de los conservatorios se centra en el alto desempeño técnico orientado hacia el virtuosismo, de modo que la notación musical ya no tiene un rol orientativo como en el canto llano, sino que apunta hacia la fidelidad interpretativa conforme el discurso compositivo (Holguín, 2017). La música se comprende entonces como una de las bellas artes, alcanzando un sentido estético que refleja la colonialidad del ser porque se marcan diferencias entre quien compone la música, quien la interpreta y quien la consume (Holguín y Shifres, 2014). En este marco, Shifres y Gonnet (2015) presentan la pedagogía denominada como modelo conservatorio, pues prevalece la instrucción individual y el sentido profesionalizante de la formación musical, tanto desde la perspectiva individual como colectiva. El modelo conservatorio, sin embargo, presenta el riesgo pedagógico de utilizar intencionalmente la violencia psicológica para instar la potenciación competencial-musical, lo que, según Fernández (2018), da lugar a frustraciones emocionales que podrían causar el abandono de la carrera musical. 
Han surgido numerosos métodos didáctico-musicales durante el siglo XX que apuntan a la adquisición de competencias musicales elementales en los términos que define el modelo conservatorio, destacándose el método "Tonic Sol-Fa", los métodos activos ligados a Dalcroze o Martenot, los métodos instrumentales como Kodály, Orff o Suzuki, así como también los métodos creativos vinculados a Paynter o Schafer (Hemsy de Gainza, 2004). Si bien los métodos expuestos fueron creados en el Norte Global, también han surgido propuestas en América del Sur, sobresaliendo a nivel internacional las prácticas orquestales infanto-juveniles como "El Sistema".

Es preciso enfatizar que Jorge Peña Hen fue el precursor de tal formato de orquestas, prevaleciendo la justicia social porque el acceso no estaba condicionado a factores socioeconómicos. El Sistema en Venezuela dice apuntar a dicho objetivo, pero Baker (2019) asevera que tal cometido es más un mito que una realidad porque la propaganda mediática hace ver a "El Sistema" como un programa de justicia social, cuando ocurre lo contrario. Es decir, El Sistema no consigue llegar a los grupos socioeconómicamente más desfavorecidos (Baker y Frega, 2016). A esto, Quiroga-Fuentes y Angel-Alvarado (2021) expresan que en "El Sistema" predomina la meritocracia interpretativa, pues la incorporación a las orquestas regulares depende de las competencias profesionales que se exhiben. Por consiguiente, "El Sistema" es un programa orientado hacia la formación de talentos y no hacia la democratización del aprendizaje musical, enmarcándose entonces en el modelo conservatorio apegado al colonialismo no solo porque establece mecanismos de segregación y exclusión social, sino también porque en su repertorio prevalece una visión eurocentrista. Además, se perpetúan patrones de violencia, reportándose casos de acoso y abuso sexual (Baker, 2014), así como también campañas de desforestación (Lafontant, 2019).

\subsection{Educación musical y el gatopardismo colonial}

En 1995, Elliott publicó la filosofía praxial poniendo énfasis en la acción musical mediante la experiencia estética que surge en un contexto determinado, lo que implica dejar de ver la música como un objeto y comenzar a entenderla como una acción, reconociéndola "como una práctica humana diversa" (Elliott, 1995, p.43). Es decir, la visión eurocentrista se puso en tela de juicio, pues la música ya no se limita a las bellas artes, sino que es legítimo hablar de músicas dada la amplia diversidad cultural. Así, cobra relevancia desde la praxis el concepto musicing que se entiende como una contracción del hacer musical, de modo que se refiere al proceso musical o a la acción de llevar a cabo una práctica musical contextualizada, ya sea mediante la interpretación, improvisación, composición, conducción o confección de arreglos. Por consiguiente, las músicas se entienden como productos que se emiten o difunden. Esto revela la presencia de una espiral hermenéutica entre proceso-producto que da lugar a un dualismo sujetomúsica, ya que el proceso implica prácticas musicales contextualizadas que forjan productos musicales que son consumidos por una audiencia. La filosofía praxial, al establecer que el 
conocimiento musical se funda en la praxis y que el musicing es una "acción humana intencional" (Elliott, 1995, p.50), preserva la colonialidad del ser caracterizada por el modelo conservatorio, pues se distingue entre quien lleva a cabo la acción musical y quien la consume.

Esta mirada colonialista a la filosofía praxial no es nueva, pues se han expuesto varias críticas desde el Norte Global. Por ejemplo, Kneiter (2000) la concibe como un "enfoque de conservatorio elitista y tradicional del siglo XIX" (p.45) porque solo atiende a quienes desean y pueden dominar la práctica musical contextualizada. Westerlund (2002) considera que es insostenible porque prevalece el desarrollo de habilidades musicales individuales por sobre el sentido de comunidad de aprendizaje. Como último ejemplo, Reimer acusa que la mirada exclusiva hacia la práctica musical contextualizada "representa un conservadurismo extremo en el espectro de todas las posibles miradas filosóficas. 'La educación musical basada en la performance', con el pragmatismo como base no es nuestra solución -es nuestro problema... porque destruye cualquier esperanza" $(1997$, p.37) de proveer una educación musical que sea significativa a todo el estudiantado.

Desde América del Sur también han surgido críticas, ya que Hemsy de Gainza (2010) considera que la filosofía praxial encapsula la realidad debido a que cada persona debe "construir, como si se tratara de un rompecabezas, una práctica que podría estar a priori determinada, empobrecida, por el modelo.... El peligro reside en aquello valioso o esencial que podría perderse en medio o durante el transcurso de la misma" (p.42). Por lo tanto, la filosofía praxial va en desmedro de la praxis porque, según Lazzarin (2005), la práctica musical contextualizada podría generar estereotipos al condicionarse la realidad por patrones simbólicos, puesto que la musicalidad - como forma de conocimiento procedimental de cada individuo -es "sensible al contexto" (Elliott, 1995, p.260). En otras palabras, se puede insertar música en las situaciones didácticas, pero los contextos no pueden insertarse, sino que recrearse. Este el factor condicionante de la realidad que da lugar a sesgos y estereotipos sociales.

El concepto de gatopardismo se entiende como 'cambiarlo todo para que nada cambie', cobrando aquí relevancia porque Jorquera et al. (2020) postulan el enfoque filosófico praxial como alternativa a la educación musical latinoamericana, sirviendo como base epistemológica para redefinir los principios de los modelos jesuita y conservatorio. Tal propuesta da cuenta de la ambigüedad expresada por Hemsy de Gainza (2010) y Lazzarin (2005) porque, mientras se propone como eje transversal alejarse de la mirada universal de la música para ahondar en músicas de otras culturas, el siguiente eje da "énfasis al conocimiento y comprensión del mundo desde la educación musical” (Jorquera et al., 2020, p.13). Ambos ejes ponen el foco en la práctica musical contextualizada, aunque el primero pondría aparentemente el foco en contextos micro culturales y el segundo en contextos abstractos, pues depende de la visión individual sobre el concepto 'mundo'. Es ahí un ejemplo de la ambigüedad que condiciona la realidad, ya que, mientras un eje sugiere alejarse de la mirada universal, el que le sigue permite el acercamiento.

@ Rolando Angel Alvarado. The content of this article is the sole responsibility of the authors. The Revista Electrónica de LEEME and Universitat de València are not liable for any legal actions that may arise involving the article's content. Revista Electrónica de LEEME - Lista Electrónica Europea de Música en la Educación-. http://ojs.uv.es/index/php/LEEME/index ISSN: 1575-9563. Editores: Universidad de Valencia y Jesús Tejada. Visibilidad de esta revista: SCOPUS, Emerging Sources Citation Index (Clarivate), EBSCO, CINDOC (CSIC), Citefactor, COPAC, Dialnet, DICE (CSIC), DOAJ, e-revistas (CSIC), EBSCO Premier, ERIH+, Gale Cengage Learning, IN-RECS, IRESIE, LATINDEX, MIAR, OCLC Worldcat, RESH, REDIB, RILM Core Journals, SUDOC, ULRICHS. Esta revista es de acceso libre mediante licencia Creative Commons 4.0 CC by. Política de archivado: etiqueta verde SHERPA-ROMEO. 
La propuesta de Jorquera et al. (2020) toma como pilares epistemológicos la filosofía praxial de Elliott y los fundamentos pragmáticos de John Dewey. Sin embargo, los autores dejan entrever un enlace con la corriente musicking de Christopher Small, sin hacer hincapié en las profundas diferencias que existen entre ambas corrientes y menos aún en los fundamentos de articulación teórica. Por un lado, el musicing se funda en el pragmatismo que vincula la práctica con la teoría en una espiral hermenéutica, de modo que, al ser la música una práctica humana diversa, cobra relevancia el contexto en donde ocurre la práctica musical. Por otro lado, el musicking se comprende desde el constructivismo social, lo que da lugar a un sentido colaborativo del quehacer musical dentro de un contexto sociocultural. Por consiguiente, el musicing da relevancia a la práctica musical contextualizada y el musicking al contexto donde ocurren las relaciones musicales. Tales diferencias son importantes, ya que el musicing se apega a las ambigüedades que plantean Hemsy de Gainza (2010) y Lazzarin (2005), mientras que el musicking abre la puerta a pedagogías decoloniales.

\subsection{Educación musical en vías de decolonialismo}

Desde el constructivismo social, Small presenta el enfoque musicking o musicar (Small, 1999a), el que implica "formar parte... en una actividad musical, ya sea interpretando, escuchando, ensayando..., dando material para la interpretación (lo que se llama composición), o bailando" (1998, p.9). Por lo tanto, el musicar concibe la acción musical como un lugar de encuentro que permite configurar grupos sociales dentro de un ritual, estableciéndose roles de participación que dejan entrever esfuerzos colectivos que no se limitan al aprendizaje, sino que se extienden hacia la experiencia relacional (Small, 1999b). Esta visión comunitaria hace que el musicar sirva de base epistemológica para entender la complejidad de la actividad humana, pues permite ahondar en el cómo y el porqué de las acciones performativas tras considerarse las formas de existencia individual y social en donde se exploran, se afirman y se celebran las relaciones (Small, 1998). En este marco, Samper enfatiza que "no hay un acto de musicar más serio que otro" (2017, p.122), ya que las dimensiones de exploración, afirmación y celebración de relaciones pueden acontecer dentro de una orquesta, en una pareja de baile o en circunstancias íntimas de escucha musical.

En América del Sur, el musicar hace plausible adoptar el decolonialismo porque, en lugar de replicar o perpetuar patrones colonialistas, abre caminos para dignificar o reinventar las practicas locales desde miradas comunitarias que dan cuenta de territorialidad y memoria colectiva, pudiéndose destacar cuatro ejemplos. Desde una perspectiva indigenista, de Branco y Santos (2021) reportan que elencos musicales aymaras y quechuas no solo reafirman su identidad indígena mediante la acción performativa, sino que también refuerzan su vida cosmocéntrica y holística al concebir, por un lado, el viento como un instrumento musical altiplánico que anuncia las variaciones climatológicas y, por otro lado, la música como un elemento ritual indispensable 
para la agricultura. Desde una dimensión subjetiva, Ponce (2020) critica que la población mestiza tenga libertad para explorar y reinventar la música occidental euro-génica, pero que se le acuse de apropiación cultural cuando piensa y reinventa las sonoridades locales del territorio que habita, aun cuando es parte de la cotidianeidad social. Desde una dimensión política, Fuentealba (2021) recalca que el musicar es determinante durante la sublevación y protesta social porque la perfomance musical da cuenta de un ritual colectivo que conlleva emociones, ironías, territorialidad, identidad, sentido de comunidad, confrontación a la autoridad y recuperación del espacio público. Por último, desde una dimensión medioambiental, la Orquesta de Instrumentos Reciclados de Cateura y la Escuela de Música Toki en Rapa Nui dan cuenta de una cadena de valor que, a la vez, fomenta y cuestiona principios de sustentabilidad y justicia epistémica (Boscarino y Saraviac, 2021; Padgett, 2015).

El musicar abre campos de acción y desarrollo a la educación musical desde una perspectiva centrada en el decolonialismo. Sin embargo, se hace imperioso establecer lineamientos para que no se acepte cualquier tipo de educación musical. En este sentido, Samper (2017) destaca que la cultura occidental experimenta una crisis espiritual que confronta la fe y la razón, lo que insta a promover "una pedagogía de la escucha; de la verdadera escucha atenta y afectuosa: de sí, del otro, de la música, de los territorios y contextos culturales, de la diversidad de ritmos vitales, del cosmos, del espíritu" (p.148); sirviendo la música como lugar de encuentro experiencial para reconectar la dimensión cognitiva con la dimensión holística. Esta visión pedagógica atenta y afectuosa demanda incorporar el enfoque sociomusical, pues es una corriente que se ha instalado en el Sur Global, más allá de las fronteras de América del Sur.

En concreto, Angel-Alvarado (2018) plantea el enfoque sociomusical como una teoría que se funda en la visión holística de la educación musical, pues aportaría tanto al conocimiento micro como macrosocial, permitiendo profundizar en la identidad sociomusical conforme a principios de diferenciación del capital sociomusical. En este sentido, el capital sociomusical surge como un subtipo del capital sociocultural, puesto que tanto las experiencias personales y colectivas pueden analizarse desde el musicar, profundizando en "cosas que la gente sabe, pero que no necesita explicar" (Weidman, 2012, p.230). El capital sociomusical se distribuye en la sociedad, lo que implica que las experiencias individuales se entrelazan con la estructura social, dando lugar a una movilización sociomusical, pues cada persona internaliza de manera particular el capital sociomusical que le proveen grupos sociales específicos. En este sentido, Kippen (2002) establece que el capital sociomusical despierta una identidad sociomusical indisoluble a la genealogía, determinando posiciones sociales conforme a los comportamientos musicales que exhibe cada persona dentro de la comunidad. Sin embargo, Kippen también enfatiza que "no se puede confiar a cabalidad en ninguna genealogía o historia familiar como representación de hecho, pero eso no significa que todos los aspectos sean falsos" (2002, p.114). 
Dicho esto, el enfoque sociomusical se plantea desde el sincretismo porque entrelaza los elementos ancestrales y modernos mediante la incorporación de elementos sonoro-musicales extranjeros, electrónicos y digitales en las prácticas musicales locales (Guerrero 2007, Skinner, 2015), incitando a procesos de "preservación, adaptación e innovación" (Harnish, 2005, p.265). Es decir, el enfoque sociomusical da cuenta de intercambios recíprocos entre las comunidades colonizadas y colonizadoras, permitiendo el surgimiento de nuevas identidades sincréticas basadas en la interculturalidad y la post-etnicidad (Casas-Mas, 2018). Esta visión sociomusical es determinante porque permite valorar, dignificar y perpetuar el conocimiento local, sin rechazar ni privar el acceso al saber colonial (Serrati, 2017), ya que la identidad se construye en un ciclo interminable desde la complejidad, comprendiendo la individualidad del ser, la comunidad, la sociedad y el mundo (Angel-Alvarado, 2018). Un ejemplo al enfoque sociomusical es la Orquesta de Instrumentos Autóctonos y Nuevas Tecnologías de la Universidad Nacional de Tres de Febrero en Argentina, pues se entrelazan las sonoridades de artefactos indígenas con las tecnologías aplicadas a la música (Iglesias, 2020). Vale agregar que toda persona posee una identidad sociomusical, pero esta es nutrida o debilitada por las experiencias de vida, volviéndose crucial la promoción de comportamientos musicales participativos dentro de ritos comunitarios para romper la colonialidad del ser representada por el modelo conservatorio.

\section{Discusión y conclusiones}

El musicar orienta la acción musical hacia el Sumak Kawsay, Suma Qamaña o Küme Mogñen, pero, no es plausible asegurar que hay un acoplamiento cabal porque las visiones indigenistas, en su justo derecho, reclamarían que el musicar carece de una cosmovisión o una dimensión espiritual (Larrea, 2010; Unceta, 2013; Viteri, 2002). Por consiguiente, la teoría emergente sugiere que la educación musical asimila la visión polisémica y armónica del Buen Vivir indigenista cuando el musicar se propone pensar, dignificar y reinventar el saber local desde los criterios que define el enfoque sociomusical (Angel-Alvarado, 2018; de Branco y Santos, 2021; Guerrero, 2007; Harnish, 2005; Skinner, 2015). La reinvención del saber no abre espacios a la apropiación cultural, pues son las mismas comunidades colonizadas y colonizadoras las que incitan en reciprocidad el sincretismo que da lugar a la configuración de identidades emergentes post-colonialistas (Casas-Mas, 2018), lo que implica dejar atrás el activismo postdesarrollista para avanzar hacia modelos pedagógicos auténticos, duraderos, vivos, afectuosos, comunitarios, genealógicos y orgánicos (Boscarino y Saraviac, 2021; Kippen, 2002; Schluchter, 2011; Weidman, 2012). Por ende, la población mestiza debería poder acoger libremente el capital sociomusical sincrético (Ponce, 2020) porque son el ejemplo vivo y orgánico de la interculturalidad y la post-etnicidad.

En el polo opuesto, está el modelo tridentino, pues representa un atentado cultural al intentar cambiar, incluso por la fuerza (Battcock, 2015), los comportamientos y ritos 
cosmocéntricos, holísticos y comunitarios de los pueblos originarios mediante el adoctrinamiento político-religioso (Serrati, 2017; Tánacs, 2002). El modelo conservatorio tiende a verse como un ajuste del modelo tridentino y, aun cuando también representa una oposición al Buen Vivir, tal apreciación no es del todo cierta porque, si bien el modelo conservatorio invisibiliza, academiza y construye mitos sobre los saberes musicales de América del Sur (Holguín y Shifres, 2014; Mendívil, 2012; Salinas 2000; Vera, 2014), la instalación del Conservatorio de Paris es el hito que pone en confrontación la fe y la razón, pues la educación musical ya no se centra en la evangelización, sino que pone el foco en la formación de profesionales de la música (Holguín, 2017; Rhalizani, 2020).

Esta crisis espiritual provoca que el modelo conservatorio no solo se aplique en espacios educativos no profesionalizantes mediante métodos didáctico-musicales (Hemsy de Gainza, 2004), sino también que se camufle como propuesta contrahegemónica mediante la filosofía praxial (Kneiter, 2000; Reimer, 1997; Westerlund, 2002), pues se apegaría al Buen Vivir postdesarrollista o al decrecimiento porque el sentido de comunidad es frágil (Cubillo-Guevara, 2016; Hemsy de Gainza, 2010; Lazzarin, 2005; Oviedo, 2011). De ahí que se haya instalado el colonialismo en las repúblicas de América del Sur, expresándose musicalmente mediante el currículo escolar (Sepúlveda, 2017) y las orquestas infanto-juveniles que marcan diferencias entre intérpretes y oyentes (Baker, 2014), mientras se devastan bosques bajo la excusa centrada en la construcción de instrumentos (Lafontant, 2019). Por lo dicho, es difícil erradicar la cultura colonialista de América del Sur.

\begin{abstract}
Podríamos decir, sin dramatismos, que la situación de colonialismo interno e internalizado con respecto al mundo indio es tan profunda..., que nos hemos convertido en artífices de nuestra propia colonización. Inconscientemente, hemos contribuido a que prosperasen los elementos fetichistas y ornamentales de la identificación con el mundo indio, y con ello hemos ayudado a transformar sus organizaciones y liderazgos en una especie de emblema compensatorio que impide a la sociedad pensar qué cosa realmente es la descolonización (Rivera, 2018, p.98).
\end{abstract}

Shifres y Rosabal-Coto (2017) expresan que la colonialidad implica estructuras de poder cimentadas bajo un modelo eurocéntrico, donde se imponen "modos de conocer, ser y estar en el universo, desvalorizando otros cuerpos, lenguas, culturas, religiones, economías, formas de organización social y subjetividades" (p.86). Sin embargo, es imperioso que nuestras relaciones sociomusicales en América del Sur se sometan a un proceso de sanación que será difícil, ya que deberemos mirarnos, perdonarnos, aceptarnos y transformarnos una vez que hayamos pensado, destruido, reconstruido, aceptado y amado nuestra posición sociomusical sincrética, tanto a nivel personal como comunitaria. Desde ahí deben surgir pedagogías

en donde el cuidado de sí y del otro sean el sustrato dentro del cual germina vigorosa la planta única de cada voz individual: 'Yo soy si tú eres', dice el Sumak Kawsay o buen vivir de los pueblos americanos ancestrales subrayando el valor comunitario que tanto se ha perdido en Occidente (Samper, 2017, p.147). 
En conclusión, el Buen Vivir indigenista cobra sentido desde el musicar y el enfoque sociomusical, pues el primero da lugar a los comportamientos participativo-musicales y el segundo da cuenta de que las personas deben nutrirse de experiencias musicales para construir una identidad sociomusical. Esta nutrición no implica que la música sea el nutriente, sino que son las relaciones sociomusicales las que nutren la identidad, determinando una posición social que puede ser reflejo de la genealogía o la historia familiar o comunitaria, aunque no necesariamente las personas están sujetas o predeterminadas a repetir el patrón. Yo, de hecho, me reconozco como la única persona de mi núcleo familiar que ha adoptado la música como modo de vida, desde una mirada que nace del presente hacia el pasado en dos generaciones. Por lo dicho, es imperioso actuar pedagógicamente desde visiones que articulen el musicar con el enfoque sociomusical, pero aquello no basta, pues debemos ser capaces de someternos, ya sea desde nuestra posición nativa o mestiza, a rituales de sanación para descubrir y conocer nuestro ser y estar en la pedagogía, en la comunidad, en el colonialismo, en la interculturalidad, en la naturaleza y en lo espiritual.

Para avanzar hacia las pedagogías decoloniales vivas, auténticas y duraderas, debemos primero abrazar nuestro pasado y el presente que vivimos; desde ahí caminar, conmemorando y celebrando a quienes nos precedieron para que nos acompañen en el sendero incierto y desconocido que depara el futuro. En consecuencia, las pedagogías decoloniales surgirán de las (re)construcciones personales y, por ende, la sanación comienza en la intimidad del ser. Ahora no sabemos si surgirán muchas pedagogías decoloniales o todo se reducirá a un único modelo, pues el futuro no lo vemos. No obstante, las problemáticas medioambientales ligadas al Antropoceno y al Capitaloceno nos indican que ya es tiempo de iniciar la descolonización, lo que no debería reducirse a las relaciones humanas y culturales, pues es también imperioso reflexionar respecto al impacto que tiene nuestro quehacer sociomusical en la naturaleza y en las especies no humanas.

\section{Referencias}

Allende, G. (2014). La enseñanza de la música en la colonia: un diálogo entre el mulato Joseph Onofre Antonio de la Cadena y Herrera y los tratados heredados. (Tesis de Magíster). Universidad de Chile. https://repositorio.uchile.cl/bitstream/

Angel-Alvarado, R. (2018). La crisis de la educación musical como consecuencia de la decadencia de la institución educativa. Revista Educación, 42(2), 1-15. https://doi.org/10.15517/revedu.v42i2.29055

Baker, G. (2008). Imposing Harmony: Music and Society in Colonial Cuzco. Duke University Press.

Baker, G. (2014). El Sistema: Orchestrating Venezuela's Youth. Oxford University Press. 
Baker, G. y Frega, A.L. (2016). Los reportes del BID sobre El Sistema: Nuevas perspectivas sobre la historia y la historiografía del Sistema Nacional de Orquestas Juveniles e Infantiles de Venezuela. Epistemus, 4(2), 54-83. https://doi.org/10.21932/epistemus.4.2751.2

Baker, G. (2019). El Sistema, "The Venezuelan Musical Miracle": The Construction of a Global Myth. Latin American Music Review, 39(2), 160-193. https://doi.org/10.7560/LAMR39202

Barriga, M. (2006). La educación musical durante la Colonia en los virreinatos de Nueva Granada, Nueva España y Río de la Plata. El Artista, 3, 6-23. https://www.redalyc.org/pdf/874/87400302.pdf

Battcock, C. (2015). Para el fin que el demonio pretende: El baile y el temblor, un mal a erradicar en los Andes. Perspectivas Latinoamericanas, S, 56-68. https://docplayer.es/45549811

Bermedo, S. (2015). Dimensiones y significados que adquiere el proceso salud/enfermedad/atención en usuarios Mapuche-Williche con diabetes mellitus e hipertensión arterial. Revista Chilena de Salud Pública, 19(1), 47-52. https://doi.org/10.5354/0719-5281.2015.36339

Bernand, C. (2014). Identificaciones: músicas mestizas, músicas populares y contracultura en América (siglos XVI-XIX). Historia Crítica, 54, 21-48. https://revistas.uniandes.edu.co

Boscarino, E. y Saraviac, A. (2021). Cadena de valor de la Orquesta de Instrumentos Reciclados de Cateura. Revista Científica de la UCSA, 8(1), 57-67. https://web.archive.org/web/20210427125504id /

Bretón Solo de Zaldívar, V. (2013). Etnicidad, desarrollo y 'Buen Vivir': Reflexiones críticas en perspectiva histórica. European Review of Latin American and Caribbean Studies, 95, 71-95. http://doi.org/10.18352/erlacs.9231

Carrero, V., Soriano, R. y Trinidad, A. (2012). Teoría fundamentada Grounded theory: El desarrollo de la teoría desde la generalización conceptual. Centro de Investigaciones Sociológicas.

Casas-Mas, A. (2018). Developing an approach to the Flamenco learning-teaching culture: An innovate (traditional) learning. In B-W. Leung (Ed.), Traditional musics in the modern world: Transmission, evolution, and challenges (pp.25-40). Springer.

Cubillo-Guevara, A. (2016). Genealogía inmediata de los discursos del buen vivir en Ecuador (1992-2016). América Latina Hoy, 74, 125-44. https://doi.org/10.14201/alh201674125144 
De Branco, C. y Santos, M. (2021). Musicking Aymara and Quechua Immigrants Translocalities in Sao Paulo. Sao Paulo, 6(1), 1-27. https://doi.org/10.11606/issn.25253123.gis.2021.174364

Elliott, D. J. (1995). Music Matters: A New Philosophy of Music Education. Oxford University Press.

Estermann, J. (2012). Crisis civilizatoria y Vivir Bien. Una crítica filosófica del modelo capitalista desde el allin kawsay/suma qamaña andino. Polis, 33, 1-22. https://journals.openedition.org/polis/8476

Fernández, B. (2018). Violencia psicológica en la educación musical actual en los conservatorios de música. Revista Internacional de Educación Musical, 6, 13-24. https://doi.org/10.12967/RIEM-2018-6-p013-024

Fernández, V., Lauxmann, C. y Trevignani, M. (2014). Emergencia del Sur Global: Perspectivas para el desarrollo de la periferia latinoamericana. Economia e Sociedade, 3(52), 611-643. https://doi.org/10.1590/S0104-06182014000300003

Friggeri, F. (2021). Mariátegui: socialismo y Buen Vivir. Latinoamérica: Revista de Estudios Latinoamericanos, 72, 81-106. https://doi.org/10.22201/cialc.24486914e.2021.72.57245

Fuentealba, A. (2021). "Me sentí como si fuera invencible, como si fuéramos invencibles". Música y acción colectiva en las movilizaciones chilenas de octubre de 2019. Contrapulso. Revista Latinoamericana de Estudios en Música Popular, 3(1), 66-82. https://doi.org/10.53689/cp.v3i1.89

Guerrero, B. (2007). Identidad sociomusical de los jóvenes aymaras: La música sound. Última Década, 15(27), 11-25. http://dx.doi.org/10.4067/S0718-22362007000200002

Harnish, D. (2005). Defining ethnicity, (re)constructing culture: Processes of musical adaptation and innovation among the Balinese of Lombok. Journal of Musicological Research, 24(3-4), 265-286. https://doi.org/10.1080/01411890500234013

Hemsy de Gainza, V. (2004). La educación musical en el siglo XX. Revista Musical Chilena, 58(201), 74-81. https://revistamusicalchilena.uchile.cl

Hemsy de Gainza, V. (2010). Temas y problemáticas de la educación musical en la actualidad. Aula, 16, 33-48. https://doi.org/10.14201/7430

Holguín, P. (2017). La música desde el Punto Cero: La colonialidad de la teoría y el análisis musical en la universidad. Revista Internacional de Educación Musical, 5, 149-156. https://doi.org/10.12967/RIEM-2017-5-p149-156 
Holguín, P. y Shifres, F. (2015). Escuchar música al sur del Río Bravo: Desarrollo y formación del oído musical desde una perspectiva latinoamericana. Calle 14, 10(15), 40-53. https://doi.org/10.14483/udistrital.jour.c14.2015.1.a04

Iglesias, A. (2020). Descolonizando la música: La creación de la primera Licenciatura en Música autóctona, clásica y popular de América. Tsantsa, 10, 29-45. https://publicaciones.ucuenca.edu.ec/ojs/index.php/tsantsa/article/view/3544

Jorquera, R., Valverde, X. y Godall, P. (2020). Propuesta de principios alternativos para la educación musical en un contexto latinoamericano. Revista Electrónica de LEEME, 46, 1-16. https://doi.org/10.7203/LEEME.46.16932

Kippen, J. (2002). Wajid Revisited: A Reassessment of Robert Gottlieb's "Tabla" Study, and a New Transcription of the Solo of Wajid Hussain Khan of Lucknow. Asian Music, 33(2), 111-166. https://www.jstor.org/stable/834347

Kneiter, G. (2000). Elliott's "new" conservatory approach: A review essay. Philosophy of Music Education Review, 8(1), 40-45. https://www.jstor.org/stable/40327151

Lafontant, A. (2019). Develando el Lado Oscuro de las Maderas Tonales: Un Estudio de Caso sobre la Demanda de Instrumentos Musicales para El Sistema de Orquestas Venezolano. Action, Criticism, and Theory for Music Education, 18(3), 226-58. https://doi.org/10.22176/act18.3.226

Larrea, A. (2010). La disputa de sentidos por el buen vivir como proceso contrahegemónico. En Secretaría Nacional de Planificación y Desarrollo (Ed.), Los nuevos retos de América Latina. Socialismo y sumak kawsay (pp.15-28). SENPLADES.

Lazzarin, L. (2005). Por uma Crítica à Nova Filosofia da Educação Musical. Educação \& Realidade, 30(1), 103-124. https://seer.ufrgs.br/educacaoerealidade/article/view/23018

Lessenich, S. (2019). La sociedad de la externalización. Herder.

Mendívil, J. (2012). Wondrous Stories: El descubrimiento de la pentafonía andina y la invención de la música incaica. Resonancias, 16(31), 61-77. http://resonancias.uc.cl/images/

Merlinsky, G. (2021). Toda ecología es política. Siglo XXI.

Moreira, R. (2020). A estrutura orgânica da música na teoría Schenkeriana. (Tesis Doctoral). Universidade Federal do Estado do Rio de Janeiro. http://www.repositoriobc.unirio.br:8080/xmlui/bitstream/handle/unirio/13104/tese.pdf?sequence=1

@ Rolando Angel Alvarado. The content of this article is the sole responsibility of the authors. The Revista Electrónica de LEEME and Universitat de València are not liable for any legal actions that may arise involving the article's content. Revista Electrónica de LEEME - Lista Electrónica Europea de Música en la Educación-. http://ojs.uv.es/index/php/LEEME/index ISSN: 1575-9563. Editores: Universidad de Valencia y Jesús Tejada. Visibilidad de esta revista: SCOPUS, Emerging Sources Citation Index (Clarivate), EBSCO, CINDOC (CSIC), Citefactor, COPAC, Dialnet, DICE (CSIC), DOAJ, e-revistas (CSIC), EBSCO Premier, ERIH+, Gale Cengage Learning, IN-RECS, IRESIE, LATINDEX, MIAR, OCLC Worldcat, RESH, REDIB, RILM Core Journals, SUDOC, ULRICHS. Esta revista es de acceso libre mediante licencia Creative Commons 4.0 CC by. Política de archivado: etiqueta verde SHERPA-ROMEO. 
Nieto, M. (2021). El decrecimiento no es ninguna solución. Disjuntiva, 2(1), 7-18. https://doi.org/10.14198/DISJUNTIVA2021.2.1.1

Osses, S., Sánchez, S. y Ibáñez, F. (2006). Investigación cualitativa en educación: Hacia la generación de teoría a través del proceso analítico. Estudios Pedagógicos, 32(1), 119133. https://doi.org/10.4067/S0718-07052006000100007

Oviedo, A. (2011). Qué es el Sumakawsay. Sumak.

Padgett, A. (2015). What's New on Rapa Nui. Rapa Nui Journal, 29(1), 73-77. https://doi.org/10.1353/rnj.2016.0011

Pedrotti, C. (2009). Música y cofradías: Una institución española trasplantada a América. Revista de Musicología, 32(1), 167-175. https://doi.org/10.2307/20797971

Ponce, I. (2020). Música mestiza: una topografía de historias particulares de escucha. Post $(s)$, 6(1), 110-129. https://doi.org/10.18272/post(s).v6i1.1944

Quiroga-Fuentes, I. y Angel-Alvarado, R. (2021). Prácticas inclusivas en orquestas infantojuveniles: Un estudio de caso en Chile. ArtsEduca, 28, 140-151. https://doi.org/10.6035/Artseduca.2021.28.11

Reimer, B. (1997). Music education in the twenty-first century: Outgrowing its historically limited purposes, music education needs to be poised for an expanded mission in the twenty-first century. Music Educators Journal, 84(3), 33-38. https://doi.org/10.2307/3399054

Rhalizani, J. (2020). La música en el siglo XIX: Su relación con los fenómenos. Historia Digital, XX(35), 103-168. http://manglar.uninorte.edu.co/calamari/

Rivera, S. (2018). Un mundo ch 'ixi es posible. Ensayos desde un presente en crisis. Tinta Limón.

Salinas, M. (2000). ¡Toquen flautas y tambores!: Una historia social de la música desde las culturas populares en Chile, siglos XVI-XX. Revista Musical Chilena, 54(193), 45-82. https://revistamusicalchilena.uchile.cl/index.php/RMCH/article/view/12678/12965

Samper, A. (2017). La pedagogía del musicar como ritual social: Celebrar, sanar, trascender. El Artista, 14, 113-150. https://www.redalyc.org/jatsRepo/874/

San Martín, D. (2014). Teoría fundamentada y Atlas.ti: Recursos metodológicos para la investigación educativa. Revista Electrónica de Investigación Educativa, 16(1), 104-122. http://www.scielo.org.mx/scielo.php

@Rolando Angel Alvarado. The content of this article is the sole responsibility of the authors. The Revista Electrónica de LEEME and Universitat de València are not liable for any legal actions that may arise involving the article's content. Revista Electrónica de LEEME - Lista Electrónica Europea de Música en la Educación-. http://ojs.uv.es/index/php/LEEME/index ISSN: 1575-9563. Editores: Universidad de Valencia y Jesús Tejada. Visibilidad de esta revista: SCOPUS, Emerging Sources Citation Index (Clarivate), EBSCO, CINDOC (CSIC), Citefactor, COPAC, Dialnet, DICE (CSIC), DOAJ, e-revistas (CSIC), EBSCO Premier, ERIH+, Gale Cengage Learning, IN-RECS, IRESIE, LATINDEX, MIAR, OCLC Worldcat, RESH, REDIB, RILM Core Journals, SUDOC, ULRICHS. Esta revista es de acceso libre mediante licencia Creative Commons 4.0 CC by. Política de archivado: etiqueta verde SHERPA-ROMEO. 
Schluchter, W. (2011). Ferdinand Tönnies: comunidad y sociedad. Signos Filosóficos, 13(26), 43-62. http://www.scielo.org.mx/scielo.php

Schmelzer, M. (2021). De Maldesarrollo a Decrecimiento: Una visión posfósil y globalmente justa para las sociedades del Norte global. Gestión y Ambiente, 24(supl1), 153-174. https://revistas.unal.edu.co/index.php/gestion/article/view/91882/80064

Sepúlveda, A. T. (2017). Chile. En R. Torres-Santos (Ed.), Music Education in the Caribbean and Latin America: A comprehensive guide (pp.185-202). Rowman \& Littlefield.

Serrati, P. (2017). Cuestionar la colonialidad en la educación musical. Revista Internacional de Educación Musical, 5, 93-101. https://doi.org/10.12967/RIEM-2017-5-p093-101

Shifres, F. y Gonnet, D. (2015). Problematizando la herencia colonial en la educación musical. Epistemus, 3(2), 51-67. https://doi.org/10.21932/epistemus.3.2971.2

Shifres, F. y Rosabal-Coto, G. (2017). Hacia una educación musical decolonial en y desde Latinoamérica. Revista Internacional de Educación Musical, 5, 85-91. https://doi.org/10.12967/RIEM-2017-5-p085-091

Skinner, R.T. (2015). Bamako sounds: The afropolitan ethics of Malian music. University of Minnesota Press.

Small, C. (1998). Musicking: The meaning of performing and listening. University Press of New England.

Small, C. (1999a). El musicar: un ritual en el espacio social. Revista Transcultural de Música, 4, 1-16. https://www.sibetrans.com/trans/articulo/252/

Small, C. (1999b). Musicking - the meanings of performing and listening. A lecture. Music Education Research, 1(1), 9-22. https://doi.org/10.1080/1461380990010102

Tánacs, E. (2002). El Concilio de Trento y las iglesias de la América Española: La problemática de su falta de representación. Fronteras de la historia: Revista de Historia Colonial Latinoamericana, 7, 117-140. https://doi.org/10.22380/20274688.685

Unceta, K. (2013). Decrecimiento y Buen Vivir ¿paradigmas convergente?: Debates sobre el postdesarrollo en Europa y América Latina. Revista de Economía Mundial, 35, 197-216. http://uhu.es/publicaciones/ojs/index.php/REM/article/view/4748

Vera, A. (2014). Music, Eurocentrism and Identity: The Myth of the Discovery of America in Chilean Music History. Advances in Historical Studies, 3(5), 298-312. https://doi.org/10.4236/ahs.2014.35024 
Viteri, C. (2002). Visión indígena del desarrollo en la Amazonía. Polis, 3, 1-6. https://journals.openedition.org/polis/7678

Weidman, A. (2012). The Ethnographer as Apprentice: Embodying Sociomusical Knowledge in South India. Anthropology and Humanism, 37(2), 214-235. https://doi.org/10.1111/j.1548-1409.2012.01131.x

Westerlund, H. (2002). Bridging experience, action, and culture in music education. Sibelius Academy.

Westerlund, H., Karlsen, S. y Partii, H. (2020). Introduction. En H. Westerlund, S. Karlsen y H. Partii (Eds.), Visions for intercultural music teacher education (pp.1-12). Springer Open.

Wright, E.O. (2014). Construyendo utopías reales. Akal. 